\title{
How can we get more people with long- term health conditions involved in parkrun? A qualitative study evaluating parkrun's PROVE project
}

Helen Quirk ${ }^{1 *}$ (1) and Steve Haake ${ }^{2}$

\begin{abstract}
Background: People with long-term health conditions face barriers to physical activity and community health interventions despite potential life-changing benefits for self-management of their condition and wellbeing. A weekly mass participation running, walking and volunteering event called parkrun launched a project called PROVE in 2016 to engage people living with long-term health conditions in England. Over the 3 year project, parkrun appointed volunteer Outreach Ambassadors with a specialist interest in the health condition they represented whose role was to ensure parkrun was welcoming, supportive and inclusive. This qualitative study aimed to understand the experience of the PROVE project for people with long-term health conditions.

Methods: Semi-structured interviews were conducted with 15 PROVE Outreach Ambassadors representing 13 different long-term health conditions in England. Interviews were recorded, transcribed verbatim and analysed using thematic analysis. Rigour and transparency were sought in addition to utilising independent researchers to offer alternative interpretations of the data.

Results: Data analysis resulted in 4 overarching themes and 13 subthemes. Outreach Ambassadors believed that parkrun was already supportive of people with long-term health conditions, but that the PROVE project enabled the support to be delivered in a more structured way across health conditions and locations. Outreach Ambassadors believed that the PROVE project had the potential to create a welcoming, safe space for people with long-term health conditions to participate as walkers, runners or volunteers. Success of the PROVE project was believed to be dependent on being realistic about the potential to bring about change, challenging people's perceptions of parkrun and engaging with key stakeholders and advocacy groups. Challenges for parkrun were believed to be around communication, demonstrating impact and the project's dependence on volunteers for delivery.

Conclusions: This is the first study of its kind to explore the public health potential of parkrun for people with long-term health conditions. parkrun's PROVE project was regarded to be important for ensuring that people with long-term health conditions can engage in physical activity and volunteering in a safe and supportive environment. The findings have important implications for parkrun, policy makers and physical activity providers looking to deliver inclusive community physical activity opportunities.
\end{abstract}

Keywords: Physical activity intervention, Evaluation, parkrun, Long-term health conditions, Disability, Volunteering

\footnotetext{
* Correspondence: h.quirk@shu.ac.uk

${ }^{1}$ Centre for Sport and Exercise Science, Sheffield Hallam University, Sheffield

S10 2BP, UK

Full list of author information is available at the end of the article
}

(c) The Author(s). 2019 Open Access This article is distributed under the terms of the Creative Commons Attribution 4.0 International License (http://creativecommons.org/licenses/by/4.0/), which permits unrestricted use, distribution, and reproduction in any medium, provided you give appropriate credit to the original author(s) and the source, provide a link to the Creative Commons license, and indicate if changes were made. The Creative Commons Public Domain Dedication waiver (http://creativecommons.org/publicdomain/zero/1.0/) applies to the data made available in this article, unless otherwise stated. 


\section{Background}

In the United Kingdom (UK) more than 26 million adults have at least one long-term health condition (LTC) such as diabetes, asthma, heart failure, arthritis, dementia or depression [1]. Supporting self-management among people with LTCs is important for people's positive attitudes and behaviours, quality of life, clinical symptoms and use of healthcare resources [2]. Community-centred approaches for health offer opportunities for self-management practices that foster social inclusion, enhanced wellbeing and behaviour change, especially group activities with a focus of shared interest [3]. As one part of self-management, physical activity can be an effective way of promoting social inclusion and supporting people with LTCs to self-manage their condition, yet rates of participation by people living with a physical, intellectual or mental LTC are low compared to people not living with LTCs [4-6]. There is conclusive evidence that people with LTCs face substantial personal (e.g., pain, motivation) and environmental (e.g., architectural barriers and physical accessibility) barriers to engaging in active lifestyles $[7,8]$ and inclusive physical activity and volunteering opportunities that are appropriate for people with LTCs are urgently needed $[9,10]$.

Whilst community-based physical activity participation could be particularly important for promoting independence among adults with LTCs, a number of health inequalities (e.g., disability) exist that limit involvement for people living with LTCs. Those living with disabilities are less likely to be active compared to people without disabilities [11]. Effective, 'real world' community physical activity opportunities to tackle health inequalities are needed, especially those that involve all health condition groups. parkrun (parkrun is always written as one word with a lowercase 'p') is a community-based physical activity and volunteering event that recognises and supports the needs of people with LTCs and offers an opportunity for using the community to promote health and wellbeing. This research begins to explore the public health potential of parkrun for people living with LTCs.

Launched in 2004, parkrun (www.parkrun.com) is a rapidly growing mass participation event encouraging anyone over the age of 4 to either run, walk or wheel (buggy running and wheelchairs) $5 \mathrm{~km}$, or volunteer their time to facilitate the weekly event. parkrun takes place every Saturday morning across 22 countries, is free and welcomes people of all backgrounds and abilities. Since 2010, junior parkrun $2 \mathrm{~km}$ events for 4-14year olds and their families have been held on a Sunday morning. parkrun has a vision to create a "healthier, happier planet" [12] and aims to do so by striving to be as inclusive and welcoming as possible to people of all backgrounds and abilities. Anecdotally, parkrun is known for its community spirit and welcoming nature, and a growing body of research evidence supports the notion that parkrun is perceived as an inclusive community by those who take part [13-16].

Over 160,000 people walk, jog, run and volunteer at their local parkrun across more than 800 locations in the UK every weekend. Despite its inclusive nature and being one of the largest providers of physical activity in the UK, parkrun grew organically and was initially promoted via word of mouth. As such, certain groups and communities have been less well represented in the parkrun population [17], such as those living with LTCs and disabilities. In 2013, Stevinson and Hickson reported that just $4.3 \%$ of 7308 adult UK parkrun participants reported a limiting disability [18]. Recognising this, the parkrun management team implement targeted attempts to increase reach and engage underrepresented groups. An example of this was the PROVE project. The PROVE project (parkrun: running or volunteering for everyone) was a 3 year project launched in 2016 to increase engagement in parkrun by people living with LTCs in England. This is the first manuscript to present initial findings from the evaluation of the PROVE project.

PROVE was based on a peer support approach, led by volunteer Outreach Ambassadors with no formal training requirements or qualifications, but with a specialist interest in the condition groups being targeted. Specialist interest could be in the form of personal, lived experience of the condition either as someone living with the condition or a carer for someone with the condition, or as a health professional working in the field of that condition. Outreach Ambassadors were recruited by parkrun from volunteers in the existing parkrun community. It was the role of volunteer Outreach Ambassadors to engage with the existing parkrun community as well as the wider community of people living with the LTC they represent, working with relevant organisations or advocacy groups to strengthen parkrun's engagement with LTC populations. The Outreach Ambassadors had the responsibility of identifying the needs of people living with LTCs, designing and implementing interventions that aimed to facilitate engagement and support the positive experience of parkrun by those involved. It was one of the aims of the PROVE project to ensure that the support put in place for people living with LTCs could be delivered sustainably on parkrun's model of being volunteer-driven.

Exploring the experience of physical activity from the perspective of those living with LTCs is important to understand how to foster physical activity environments and interventions that are appropriate, supportive, safe and welcoming for all. A study into parkrun by Morris and Scott (2018) [15] involved interviews with 20 parkrun participants in the UK who had a history of mental health conditions. This study found that participants experienced parkrun as inclusive and welcoming, a safe 
environment and the familiarity of parkrun was comforting. Participants felt part of a family, valued opportunities to socialise and make friends and to identify themselves as part of a community rather than as someone with a mental health condition. In this research, Morris and Scott (2018) have made important advances into uncovering the experience of parkrun for people living with health conditions. More research into a wider range of LTCs will enable parkrun and policy-makers to recognise and respond to the specific adaptations that must be embedded in communities in order to make physical activity safe and accessible for people with LTCs [19].

This qualitative study aims to understand the perceptions of parkrun and the PROVE project for people living with LTCs from the perspective of parkrun volunteer Outreach Ambassadors. The results will have direct implications for the wider evaluation of the PROVE project, but also implications for physical activity providers, public health practitioners, stakeholders and policy makers. This manuscript presents preliminary findings from the evaluation of the PROVE project, the final evaluation results will be disseminated in a later publication.

\section{Methods}

The research methods were reviewed and approved by the local University Research Ethics Committee (reference number: HWB-2016-17-S\&E-29).

\section{Participants}

The current research sought to include Outreach Ambassadors from across the condition groups targeted by parkrun in the PROVE project. Outreach Ambassadors in England representing the following LTC groups were invited for an interview: dementia (including Alzheimer's Disease), deaf and hard of hearing, blood pressure conditions, cerebral palsy, heart conditions, endometriosis, diabetes, learning disabilities and/or autism, obesity, asthma, multiple sclerosis, mental health, musculoskeletal conditions.

The rolling recruitment of Outreach Ambassadors occurred between March 2017 and August 2018 using a purposeful sampling procedure. Outreach Ambassadors who were within 2 months of being appointed to their role were invited via an email sent out by a member of parkrun staff with the research information sheet. In total, 33 Outreach Ambassadors were invited for an interview (the number of Outreach Ambassadors in role at the time of recruitment). Invitees were asked to contact the research team directly to express their interest in participating. Those willing to participate in a telephone interview signed a consent form electronically prior to the telephone call being arranged. Fifteen Outreach Ambassadors (45\%) gave written consent to be interviewed. A mutually convenient interview time was arranged with the lead researcher on the evaluation team (HQ).

\section{Data collection}

Data were collected by the lead researcher $(\mathrm{HQ})$ via semistructured interviews with parkrun Outreach Ambassadors across England. The interviewer was the lead researcher $(\mathrm{HQ})$ who is trained in qualitative research. $\mathrm{HQ}$ is a female researcher in the field of exercise psychology with personal experience of parkrun as a runner, walker and volunteer. Interviews took place between March 2017 and August 2018 over the telephone and were recorded using a digital sound recording device and telephone pickup. The interviewer aimed to create a free-flowing discussion directed by the interviewee in an informal conversational style. The questions used were open-ended and an interview schedule was used to ensure consistency across interviews. Interview questions included:

- Can you describe your experience of parkrun?

- How does parkrun support people who have a LTC?

- What do you think about the PROVE project?

- What motivated you to get involved with the PROVE project?

- What would success look like to you? / What changes do you expect to see?

- What skills and qualities do you believe are important for your role as a parkrun Outreach Ambassador?

- What challenges do you foresee with your role as a parkrun Outreach Ambassador?

One interview was conducted in written format via email (i.e., asynchronous online interview [20]) due to the participant being unable to communicate via telephone. The written format involved extracting questions from the interview guide and included any probes that the interviewer would have used in a spoken interview. Interview length ranged from 17 to $61 \mathrm{~min}$ and the mean interview duration was $36.4 \mathrm{~min}$.

\section{Data analysis}

Audio recordings of the interviews were transcribed verbatim by an external transcription company. Data were analysed thematically by the lead researcher (HQ). Thematic analysis [21] was an iterative process that involved familiarisation with the data (reading and re-reading), generation of initial codes, searching for themes (grouping similar codes into themes), reviewing potential themes, defining and naming themes and sub-themes and finally writing up the themes. Data analysis started with an inductive approach (deriving primarily from the data) and was then deductive (based on key areas of interest covered by the interview questions).

The lead researcher (HQ) showed rigour and transparency (e.g., through reflective practice and being explicit about their position and with research decisions) and 
sought findings that would have practical implications. This was in addition to utilising a small team of independent researchers as 'critical friends' to offer alternative interpretations of the data and codes, credibility checks and support in the refinement of themes [22]. Reflexivity refers to the process of critically reflecting on the knowledge produced during the research process and the researcher's role in producing that knowledge [21]. The lead researcher made notes of any preconceptions, impressions, ideas and early interpretations of the data throughout the research process and was conscious to make note of any personal biases. The research process contained unavoidable bias as the researchers on the evaluation team are parkrun participants. Reflective practice enabled the lead researcher to address these biases and consider preconceptions and expectations prior to conducting interviews (e.g., what are your thoughts about parkrun?); and to acknowledge biases and feed reflexive insight into the conduct of interviews (e.g., what influence might my own assumptions have on the interview and findings generated?). A similar approach to rigour and reflexivity has been used in previous parkrun research [15].

\section{Results}

Fifteen parkrun Outreach Ambassadors representing 13 different LTC groups were interviewed. Participants varied across three categories; living with the LTC $(n=8)$, carer of someone with the LTC (carer; $n=3$ ), specialist working in the field of the LTC (specialist; $n=4$ ). Precise data about the length of time as Outreach Ambassador was not available, but it was intended that all interviewees were within 2 months of being appointed to their role. Demographic details of the sample (sex, age, occupation etc.) were not collected.

The main themes and sub-themes are described, with direct quotes taken from participants to help demonstrate the findings. Quotes are labelled with characteristics of the participant, but to protect confidentiality we have not provided details of the LTC they represent.

The analysis of the interviews resulted in four overarching themes and 13 subthemes that capture the perceptions of parkrun Outreach Ambassadors (see Table 1).

\section{Theme 1: existing support for parkrunners with LTCs Sub-theme 1a: parkrun has always been supportive of people with LTCS}

The Outreach Ambassadors were unanimous in their opinion that parkrun has always been supportive of people living with LTCs. This support was exemplified by the belief that parkrun has always been a welcoming and inclusive community for all. Comments from Outreach Ambassadors in reference to the supportive parkrun community included; "parkrun has always been a very welcoming space" (P11, living with the LTC); "there's nothing formal, I would say but everybody was welcomed in one way or another" (P02, carer); "actually being part of a community and just having that extra social aspect of it really made a difference" (P13, living with the LTC); and "there have been other people at parkrun who didn't widely advertise the fact that they had conditions or disabilities, ranging from MS (Multiple Sclerosis) to Parkinson's, but everybody has been very supportive of them" (P05, living with the LTC). When asked how the support from parkrun differed to other sport or physical activity programmes, one Outreach Ambassador answered; "I think it's the removal of competitiveness: the idea that it's not a race ... at parkrun no-one really asks what your time is ... so removing that pressure makes a huge difference, and that's I think why it's such an inclusive community" (P13, living with the LTC).

\section{Sub-theme 1b: support from parkrun to engage those with LTCS could be more structured}

Whilst the parkrun organisation and parkrun community was deemed to be supportive of people with LTCs prior to the PROVE project, the Outreach Ambassadors had not witnessed any logistical support, formal policies or supportive resources offered by parkrun to people living with LTCs. One respondent suggested that prior to the PROVE project, there was; "probably a lack of information about how we should support people, or how we should make it even more inclusive and encourage other people to come along as well" (P02, carer). Whilst another Outreach Ambassador suggested that; "there was some support, but only in 'pockets', it wasn't done properly" (P03, carer). It was generally believed that the level of support provided by parkrun for people with LTCs prior to the PROVE project lacked structure. For example:

"There are instances where people who, whilst there's no formal structure, have a huge amount of support. At the same time that doesn't always happen, and there are parkruns that, through omission rather than by aim, don't make it particularly easy for those with long-term conditions." (P08, living with the LTC)

The consensus among those interviewed was that parkrun, whilst being inclusive already, had the potential to be more inclusive of those with LTCs; "parkrun is inclusive but it still could be a lot more inclusive" (P09, carer).

\section{Sub-theme 1c: the PROVE project is a strategic approach to inclusivity and publicity}

The PROVE project was valued as a targeted attempt at increasing physical activity opportunities for people with LTCs. One Outreach Ambassador said, "It's a great project in terms of what it's trying to do. It hits on many 
Table 1 Overview of themes and subthemes derived from interviews from parkrun Outreach Ambassadors

\begin{tabular}{|c|c|c|}
\hline Theme & Theme label & Sample quotes \\
\hline Theme 1 & Support for parkrunners with LTCS & \\
\hline Sub-theme 1a & parkrun has always been supportive of people with LTCS & $\begin{array}{l}\text { "there's nothing formal, I would say but everybody was } \\
\text { welcomed in one way or another" (P02, carer) }\end{array}$ \\
\hline Sub-theme $1 \mathrm{~b}$ & $\begin{array}{l}\text { Support from parkrun to engage those with LTCs } \\
\text { could be more structured }\end{array}$ & $\begin{array}{l}\text { "There are instances where people who, whilst there's no } \\
\text { formal structure, have a huge amount of support. At the } \\
\text { same time that doesn't always happen, and there are } \\
\text { parkruns that, through omission rather than by aim, } \\
\text { don't make it particularly easy for those with long-term } \\
\text { conditions." (P08, living with the LTC) }\end{array}$ \\
\hline Sub-theme 1c & $\begin{array}{l}\text { The PROVE project is a strategic approach to } \\
\text { inclusivity and publicity }\end{array}$ & $\begin{array}{l}\text { "It's a great project in terms of what it's trying to do. } \\
\text { It hits on many different agendas and government } \\
\text { initiatives trying to get the inactive active, which is } \\
\text { great" (P15, specialist) }\end{array}$ \\
\hline
\end{tabular}

Theme $2 \quad$ Perceptions of what success would look like for the PROVE project

Sub-theme $2 a \quad$ Encouraging more parkrun participants who have LTCS

Sub-theme $2 b \quad$ Creating a safe space for people with LTCS

Sub-theme 2c Being able to demonstrate sustainability of the PROVE project

Theme 3

sub-theme $3 a$

Sub-theme $3 b$

Sub-theme $3 c$

Sub-theme 3d

Theme 4

Sub-theme $4 a$

Sub-theme $4 b$

Sub-theme $4 c$
Engaging with key stakeholders and advocacy groups

Selecting Outreach Ambassadors with appropriate qualities

\section{Contributors to PROVE project success}

Being realistic about the potential for change

Challenging perceptions of what parkrun is and who it is for

Anticipated challenges for the PROVE project

parkrun communication channels have limited reach

Difficulty demonstrating impact

Success is dependent on volunteers
"The ultimate success would be increased numbers of people with [health condition] taking part, that's the overriding objective" (P09, carer)

"A longer term aim is to influence healthcare professionals, politicians and third sector agencies like charities to promote ... that parkrun is a safe place, to give doctors confidence to tell people go along." (P11, living with the LTC)

"in terms of a sustainable model, volunteers is a great way, because it's cost-effective" (P15, specialist)

"readjust and focus more on certain conditions where there's a lower level of participation" (P15, specialist)

"what we really need to be trying to get out there is, it is acceptable to come along to parkrun and walk" (P05, living with the LTC)

"Being recognised by the health service and by the advocacy groups for the conditions is key" (P05, living with the LTC)

"Passion. Persistence. Resilience. Stamina. Optimism" (P03, carer)

"The limitations will potentially come from lines of communication not being robust enough" (PO3, carer)

"How do we know whether or not people have been encouraged to attend?" (PO2, carer)

"It's a massive piece of work, and to undertake it on top of your day job can be a bit difficult. So it's about being realistic about what you can and can't achieve in a short timescale" (P01, specialist) different agendas and government initiatives trying to get the inactive active, which is great" ( $\mathrm{P} 15$, specialist). It was believed that the PROVE project provided a structured, strategic approach to inclusivity by enabling parkrun to raise awareness of LTCs and deliver support consistently across the community and across locations, with specific aims and objectives. The PROVE project was regarded as an opportunity to learn about the needs and desires of people living with LTCs so that parkrun can be aware and sensitive to these when providing physical activity opportunities that are appropriate for people from all backgrounds and abilities. For example, one Outreach Ambassador described how there are; "certain things that we haven't realised would stop people coming to parkrun. Like the crowd anxiety and some of the ways that you read out an event briefing" (P13, living with the LTC).

In terms of the strategic priorities of PROVE, it was recognised that the PROVE project had two overarching aims; 1) to support existing parkrun participants living with LTCs by improving their experience and promoting continued participation, and 2) to encourage non-parkrun 
participants living with LTCs to take part in parkrun, as captured by the following:

"Actually there are already lots of people with [health condition] who are doing parkrun. And we know that those aren't our target audience because they're already at parkrun and doing parkrun, although building a community for them has been part of our [PROVE] project. ... So that's great, but to be honest those aren't our target audience, key audience. It is those people who aren't parkrunning yet, to try and get them to come along" (P07, living with the LTC)

Outreach Ambassadors also believed that the PROVE project gave parkrun the outlet for promotion and publicity to people with LTCs who may not be aware of parkrun or have not considered it an accessible activity. For example; "the difference between now and prior to [the PROVE project] is there's a real focus on encouraging people and making it easier for people to access parkrun, and then actively going out and publicising it to different communities" (P02, carer). One Outreach Ambassador captured how the PROVE project differed from previous parkrun publicity techniques:

"I would say that the PROVE project is completely counterintuitive to everything else that parkrun has done in the past. And what I mean by that is all parkruns appear to grow organically. They aren't encouraged to advertise, they aren't encouraged to go to clubs, they aren't encouraged to go to the press, they aren't encouraged to market; they grow organically through word of mouth. Whereas the PROVE project is actively making things easier for people with preconceived ideas or preconditions to say, look, why not come along and join. So it's an interesting diversion and interesting change of strategy" (P05, living with the LTC)

Theme 2: perceptions of what success would look like for the PROVE project

Outreach Ambassadors were asked what they would deem successful outcomes for the PROVE project and this theme captures the most common responses.

\section{Sub-theme 2a: encouraging more parkrun participants who have LTCS}

Respondents believed that increased numbers of parkrun participants living with LTCs would be indicative of PROVE project success. One respondent commented; "The ultimate success would be increased numbers of people with [health condition] taking part, that's the overriding objective" (P09, carer).
Whilst numerical evidence of increasing participation numbers was believed to be a desirable outcome, respondents acknowledged that being able to measure any increase in numbers of participants would be difficult, for example:

"Ideally we would have something measurable that shows that we've supported people joining [parkrun] ... but how we measure that is probably a challenge. It could be measured on how many [relationships with] organisations, charities are set up" (P13, living with the LTC)

An alternative to having numerical evidence was to have qualitative or observational data in the form of stories, case studies and observations. For example, respondents believed a successful outcome for the PROVE project would be to witness more parkrun participants with LTCs at parkrun events and to be able to produce case studies to demonstrate participation, for example; "more qualitative data, stories from people who said they didn't do parkrun and it wasn't for them and now they do it and think it's for them" (P11, living with the LTC) and; "[success] is seeing more people with conditions at parkrun in different roles. Whether they'd be walking, running, in their wheelchairs, volunteering, or watching" (P14, living with the LTC). An Outreach Ambassador had witnessed this type of success story on the Facebook group launched as part of the PROVE project to help parkrun participants with LTCs connect with others:

"Someone had posted, 'I've been a member of the [Facebook] group for some weeks, my doctor told me I need to be more active, I've been really nervous about it, blah, blah, blah. But I went and did my first parkrun this weekend and it was brilliant. Thank you to the group for all the advice'. And she'd had lots of [encouragement], nothing very remarkable or practical, but really 'oh come on, just do it, it'll be fine, don't worry about it' sort of advice - and that was what she needed to get her off the sofa and out to parkrun, so fantastic. We're building a community that will support that." (P08, living with the LTC)

An Outreach Ambassador suggested that seeing increased numbers of parkrun participants who have LTCs would raise awareness among the rest of the parkrun community:

"A by-product of all this [PROVE project] is just raising awareness in the community generally. So if you're somebody who's never met someone with [health condition] and suddenly you start seeing people with [health condition] taking part [in parkrun] it challenges stereotypes and prejudices and it will hopefully help people not make assumptions. But it's hard to measure that." (P09, carer) 


\section{Sub-theme 2b: creating a safe space for people with LTCs to be active}

Respondents believed that another indicator of PROVE project success would be to provide a supportive, safe space for people with LTCs; "to provide a community and supportive space where people can get advice from likeminded people, support and encouragement" (P11, living with the LTC). 'Safe' was defined in terms of parkrun events being welcoming and reassuring, as described:

"The first stage of it is to make parkrun, the parkrun community ... a safe space. And where people who have [health condition] or are at risk of [health condition] can turn up and feel comfortable. Where the people who are running the event or involved in the event or involved in the community feel comfortable with them being there, and basically lower those barriers to entry." (P08, living with the LTC)

Respondents believed that a successful outcome would involve this 'safe space' becoming the norm at parkrun events and parkrun event teams having an awareness of LTCs, for example:

\section{"[Success would mean] that we eventually spread the word, and are so successful that everybody becomes so mindful and so aware of LTCs and the impact they can have, that it becomes almost normal and the setting up of new parkruns will take the needs of everybody into consideration" (P01, specialist)}

For one Outreach Ambassador, creating this 'safe space' involved; "making sure that everything that we put out, or any campaign that we do is really well thought out, that the language is right and there's nothing that's going to trigger anything" (P13, living with the LTC).

One way of promoting the safe space was thought to be through making contact with health professionals and establishing partnerships with advocacy groups and policy makers, who could endorse and promote parkrun to people living with LTCs:

"A longer term aim is to influence healthcare professionals, politicians and third sector agencies like charities to promote ... parkrun as a safe place, to give doctors confidence to tell people go along." (P08, living with the LTC)

\section{Sub-theme 2c: being able to demonstrate sustainability of the PROVE project}

It was believed that success would be demonstrated if the impact of the PROVE project demonstrated longevity over time. An Outreach Ambassador believed that sustainability would involve the Outreach Ambassador role becoming redundant because; "there won't be a need for any Outreach Ambassadors as such, because everybody will think in the same way" (P01, specialist). One Outreach Ambassador believed that being volunteerdriven facilitated sustainability, "in terms of a sustainable model, volunteers is a great way, because it's cost-effective" (P15, specialist).

\section{Theme 3: contributors to PROVE project success}

Respondents believed that the success of the PROVE project was dependent on the following factors; a) being realistic about the potential for change, b) challenging perceptions of what parkrun is and who it is for, c) engaging with key stakeholders and advocacy groups d) having Outreach Ambassadors with important qualities such as communication skills and experience of the LTC they represent.

\section{Sub-theme 3a: being realistic about the potential for change}

Success was believed to be dependent on having a realistic vision of the potential outcomes of the PROVE project and being realistic about the scale of the task given the limited resource available. Respondents acknowledged that it was important to be realistic about what the PROVE project could achieve, for example; "what will give us the biggest impact from the least amount of intervention, small things that can have a big impact... not being overly ambitious and starting small" (P11, living with the LTC). Likewise, an Outreach Ambassador talked about having realistic outcomes; "parkrun is not a cure [for LTCS] ... It doesn't sort out these problems. But it does put people in an environment where they feel empowered and they feel able to exercise" (P08, living with the LTC).

To overcome the large scale of the project, one respondent suggested that a realistic approach would be to prioritise certain LTC groups, "readjust and focus more on certain conditions where there's a lower level of participation" (P15, specialist). Overall, respondents believed it was realistic to think about subtle changes to the parkrun organisation and environment, such as raised awareness among the parkrun community and parkrun event teams, for example:

"I think we need to do some more stuff to raise awareness in the event teams and amongst the parkrun ambassadors about that. And I think that's probably about as far as it goes. It would be lovely in an ideal world to have an amazing amount of resource of people who could parachute in to local events to support people with [health condition] if they wanted to run for the first time. But that doesn't really fit the parkrun ethos, nor is it particularly practical." (P08, living with the LTC) 
Outreach Ambassadors believed that it was reasonable to use the PROVE project as an opportunity to learn, but that the impact would be subtle:

"I see it [the PROVE project] as almost like a proof of concept pilot project, which is a vehicle for learning ... analysing it, I'd like to see all that knowledge and data being used to learn ... how we can learn to reach the difficult ones to get involved." (P04, specialist)

"I'd say the ethos of parkrun is that it doesn't change. It's so successful as a format and a concept I'm not sure that anybody wants it to change. I think it's really just about who gets involved, an awareness of the people who are involved ... . the change is subtle." (P04, specialist)

\section{Sub-theme 3b: challenging perceptions of what parkrun is and who it is for}

Respondents believed that success for the PROVE project was dependent on parkrun being accepted as an activity that is appropriate for everybody of all abilities, including people with LTCs, for example; "we need to break down the stigma and preconceived ideas that people have got about what people living with LTCs can and can't do" (P01, specialist). It was believed that misconceptions about parkrun could be a deterrent to participation among some people with LTCs; "people's own perceptions put them off before they even arrive there, but you realise when you're at parkrun it's not too bad... I think fear is quite a lot of what people's concerns are" (P10, specialist). In relation to this, it was common for Outreach Ambassadors to refer to people's "mind-sets" about physical activity for people with LTCs; "Just trying to broaden people's mind-sets. I think a lot of ladies with [health condition] have a fixed mind-set that exercise is not for them" (P06, living with the LTC).

There was a belief that for the PROVE project to be successful, parkrun should be accepted as a walking event as well as a running event, for example; "what we really need to be trying to get out there is, it is acceptable to come along to parkrun and walk" (P05, living with the LTC). Some respondents felt the need to challenge the perception that parkrun was only for runners, for example; "PROVE is about actively promoting that you can walk or jog it, despite the name 'parkrun'" (P11, living with the LTC). Another Outreach Ambassador reflected upon the preconceptions people can have about parkrun:

"There's this perception out there that people who run have got to be runners, they've got to be running about like Dave Bedford in singlets and be super fit. But I think that view has changed over the years with the jogging generation and the growth of things like the
London Marathon, the Great North Run, the Race for Life. I think parkrun can continue that without having to go down the field of becoming 'parkwalk' for instance. I think if it became 'parkwalk' it would put the runners off, and actually it did start with the runners. The clue's in the name: parkrun. But we do say welcome to all. So I would like to see that we still have people who are not afraid to come up and run, but people who aren't afraid to come and walk too." (P05, living with the LTC)

\section{Sub-theme 3c: engaging with key stakeholders and advocacy groups}

Outreach Ambassadors believed that the success of the PROVE project was dependent on engagement with key stakeholders and advocacy groups associated with different LTCs, believing that this would help reach a wide range of people in the general population; "that's how we can actually get that sort of message across" (P02, carer). Another Outreach Ambassador agreed that engagement with advocacy groups such as national charities was the key to broadening the PROVE project's reach; "I think that's the key to opening parkrun up to more people" (P06, living with the LTC).

An Outreach Ambassador suggested that engagement with key stakeholders might depend on parkrun being recognised and valued as a health intervention, for example; "being recognised by the health service and by the advocacy groups for the conditions is key" (P05, living with the LTC). Another Outreach Ambassador suggested that working alongside healthcare professionals would be advantageous for ensuring the right messages are being communicated to people with LTCs; "The last thing I want to do is turn up and talk to someone with a heart condition where running is the last thing that they should be doing ... we need to work more hand in hand with the professionals" (P05, living with the LTC).

\section{Sub-theme 3d: selecting outreach ambassadors with appropriate qualities}

Respondents were asked to describe the qualities needed to be successful Outreach Ambassadors. The majority described a passion for change and making a difference. Communication and experience of the condition were also believed to be important. The following descriptions were provided by the Outreach Ambassadors:

"To be a good communicator, to be a good listener, to be aware of the developments that are happening around you, and to not be confined by your own thinking, be willing to listen to what other people have got to say" (P01, specialist)

"Passion. Persistence. Resilience. Stamina. Optimism" (P03, carer) 
"Really good communication skills. Especially when you're putting things on a [Facebook] group, it needs to be worded carefully so its emotive but it doesn't make people feel guilty ... being organised, having good empathy, being a team player, having a good understanding of the aims of the project ... action planning, reflective, being aspirational in terms of what you hope to achieve" (P06, living with the LTC)

"Empathy with the condition and an awareness of the limits of the role"... "non-prejudice" (P10, specialist)

"nothing about us without us ... it's about people with the condition or disability saying this is my experience, this is what I need, I'm an expert by virtue of my experience and I think that's fundamentally important to the PROVE project ... I don't think it would work without that" (P11, living with the LTC)

It was believed that the autonomy given to Outreach Ambassadors was an important driver for PROVE project success. One respondent suggested, "It's not a top down approach, micro-managing the volunteers ... it's very much a free sort of thing, to come and do as and when you can on the project and do what you can" (P15, specialist).

\section{Theme 4: anticipated challenges for the PROVE project}

The Outreach Ambassadors recognised a number of challenges for the PROVE project. Whilst the PROVE project was considered to have realistic aims and objectives that align well with the overall parkrun strategy, it was considered a large, challenging task; "it's challenging and each [condition] group will have different challenges" (P02, carer). One Outreach Ambassador described the size of the challenge as "phenomenal":

"I think it's just an absolutely phenomenal challenge. You know, the NHS and the government are trying to do this and have got millions of pounds and then it feels like there are us parkrun Outreach Ambassadors, ... it does feel like a massive, massive task. But then parkrun is a massive thing." (P07, living with the LTC)

The subthemes capture the main challenges perceived by respondents that relate to methods of communication, difficulty demonstrating impact and the dependency on volunteers.

\section{Sub-theme 4a: parkrun communication channels have limited reach}

The Outreach Ambassadors believed that the word-ofmouth publicity of parkrun has resulted in internal communications among like-minded people, for example:
"It's easy to get like-minded people involved. It's getting people, the people who aren't of the same kind of mind-set involved who could benefit, so maybe there's a challenge there ... I'm not sure that the objectives of the PROVE project are going to touch the people that we as a society need to reach" (P04, specialist)

The main belief among the Outreach Ambassadors was that for the PROVE project to be successful, its communication, reach and engagement "needs to go outside of parkrun" (P10, specialist) and reach the nonparkrun community.

There was also reference to the communication of PROVE project activity within parkrun, with some Outreach Ambassadors suggesting that the project's aims and reach are not well understood among existing parkrun participants, for example; "if you're a normal parkrunner you might only get snippets of the different conditions and not realise that we've got this entire [PROVE] programme that supports lots of different ones" (P13, living with the LTC). Communication was particularly important for the Outreach Ambassador for deaf and hard of hearing, who believed that communication barriers could be a problem; "The limitations will potentially come from lines of communication not being robust enough" (P03, carer).

\section{Sub-theme $4 b$ : difficulty demonstrating impact}

Another challenge perceived by the Outreach Ambassadors was in demonstrating the impact of the PROVE project. As demonstrated in Theme 3, respondents believed that to be successful, the PROVE project would need to demonstrate an increase in the numbers of parkrun participants with LTCs participating. Yet respondents were unsure whether this is possible; "how do we know whether or not people have been encouraged to attend?" (P02, carer).

Outreach Ambassadors also perceived the challenge of knowing how much of an increase in participation would be regarded a success; "One of the challenges is - we've got some baseline figures, but it's going to be hard to actually quantify it" (P09, carer). Another Outreach Ambassador described their concern in quantifying impact:

"I don't know what an acceptable number of new parkrunners would be, if we get 10 new people, would that be an achievement or 100 or ... ?... If at the end of it we go, well, actually, do you know what, we know that we got 10 people with [health condition] to be more active, and we give ourselves a big pat on the back, but what I'm not sure on is what is considered a success?" (P07, living with the LTC)

Given the challenges of demonstrating impact numerically, the respondents believed that impact would need 
to be demonstrated in different ways, particularly, "what the participants feel, their life changes, actually how it's impacted and changed their lives completely ... that side of stuff is very important to measure ... the life outcomes, life skills" (P15, specialist).

\section{Sub-theme 4c: success is dependent on volunteers}

Another challenge cited by the Outreach Ambassadors was the limitations associated with the PROVE project being dependent on the work of volunteers for its delivery and the realisation that; "there's only so far you can take the voluntary sector" (P05, living with the LTC). Another respondent explained; "It's a massive piece of work, and to undertake it on top of your day job can be a bit difficult. So it's about being realistic about what you can and can't achieve in a short timescale" (P01, specialist). The same Outreach Ambassador who believed that the volunteer-driven approach was the most sustainable model also believed that this introduced, "limitations of what it might achieve" (P15, specialist) because of other responsibilities and time constraints.

Some respondents were concerned about the extra burden that might be placed on volunteering parkrun event teams if the number of parkrun participants living with LTCs increased significantly. One respondent suggested that success of the PROVE project might depend on upskilling volunteer event teams (the parkrun volunteers delivering the events in local communities), "so you could give them some skills to then help and support engage people with the health condition or disability in parkruns. So they are upskilled enough to then support people" (P15, specialist). However, there was evidence of concerns about placing too much burden on volunteers, for example; "everything we do is with the awareness that event teams are volunteers and we can't place too much burden on them" (P11, living with the LTC) and also; "it's all been done on a low level volunteer basis ... we're putting a big onus on the volunteers and a big weight on their shoulders ... being asked to be welcoming to all and they may not be able to handle it" (P05, living with the LTC).

\section{Discussion}

Physical activities with a focus on community and shared interest have been recommended [3], but practical examples of approaches to promote physical activity among people living with LTCs are needed [23]. parkrun launched the PROVE project to promote participation and support the experience of parkrun among people living with LTCs. This research interviewed parkrun volunteer Outreach Ambassadors to explore the perceptions of the PROVE project for people living with LTCs. The findings support previous research that has shown how parkrun is regarded as an inclusive community physical activity opportunity [13-15]. It also demonstrates the perceived benefits that parkrun's PROVE project has had for people living with LTCs. According to the perspective of the Outreach Ambassadors interviewed, the PROVE project was welcomed by parkrun participants who have LTCs and praised for enabling a more structured and consistent approach to welcoming people to parkrun and supporting their positive experience.

According to the Outreach Ambassadors, the PROVE project had the potential to enable parkrun to be a safe and welcoming space for people with LTCs to engage in physical activity and volunteering. parkrun's ability to create social support networks in communities supports Public Health England's [3] request for social network approaches that focus on strengthening community and social support between people, via collective or community activities. Rimmer and Marques [9] outlined the urgent need for approaches that integrate people with LTCs into existing community-based physical activity services. Guidelines for the implementation of community-based health promotion programmes for people with disabilities state that communities should provide socially engaging physical activity environments that will allow people with LTCs to engage in physical activity with other community members [24]. The guidelines recommend that disability and non-disability service providers must work together to form inclusive health coalitions that represent the physical activity needs of community members with LTCs. The communities created by parkrun and the PROVE project, either in real life or online (i.e., via Facebook support groups) were regarded as important for creating social networks and breaking down barriers to physical activity and/or volunteering for people living with LTCs. This supports previous research demonstrating the mental health benefits of being identified as part of the parkrun community [15]. The current findings demonstrate the importance of people living with LTCs feeling part of a social community and the potential role that parkrun could have in offering inclusive physical activity and volunteering opportunities (i.e., parkrun's 'social capital'). The role of 'social capital' in shaping participation in parkrun has been explored previously [25] and further investigation is needed into how social relationships as sources of support may promote participation among people living with LTCs. The PROVE project provided parkrun with the opportunity to engage with people living with LTCs to better understand their needs and desires and take these into consideration when designing and delivering targeted interventions to promote parkrun to wider audiences.

According to the Outreach Ambassadors interviewed, success of the PROVE project was believed to be dependent on being realistic about the potential for the project to bring about measurable change given the financial, time and resource limitations of the volunteer sector. Success was also deemed to be dependent on 
parkrun successfully challenging misconceptions that parkrun is for runners only. Previous parkrun research presents examples of how acceptance and provision for individuals with visual impairments and welcoming groups of Nordic walkers demonstrates the potential for parkrun to attract 'non-traditional' populations [13, 26], but the current findings suggest that more can be done to communicate that parkrun is welcoming and inclusive to all. Guidelines for health promotion programmes for people with disabilities suggest that opportunities should be socially, behaviourally, and environmentally accessible [24]. Whilst the current study suggested that parkrun is deemed a 'safe space' and physically accessible for some people with LTCs, which supports previous findings [15], lack of accessibility might be perceived by others. Attempts should be made to ensure that events like parkrun and their communication channels are accessible for all, but that they are perceived as welcoming and appropriate for all.

The Outreach Ambassadors interviewed identified a number of challenges for parkrun in delivering the PROVE project. Outreach Ambassadors had concerns about communication barriers, which could be pertinent to some LTCs more than others. For example, individuals who are deaf or hard of hearing will not necessarily learn about parkrun from channels such as social media and newsletters, thus communications involving talking newspapers or British Sign Language are important considerations [24]. Similarly, people with learning disabilities may have communication barriers requiring accessible documents and easy read information. Thus, to optimise the success of the PROVE project and similar initiatives it is important for parkrun to establish communication methods that reach widely both within and outside the parkrun community. To facilitate this, forming partnerships with key advocacy groups and charities at regional and national level would enable parkrun to reach the nonparkrun community with messages and promotion. Prescribing parkrun has been formally recognised in the UK by the Royal College of General Practitioners (RCGP). This new partnership with RCGP involves parkrun events linking with their local GP practice who become certified as 'parkrun practices' with clinical champions referring parkrun to patients and their cares $[27,28]$. It would be beneficial for events like parkrun to work with healthcare professionals specialising in LTCs to ensure that messages are appropriate for different health conditions and to encourage the 'social prescription' of physical activity to people living with LTCs.

There are wider implications of the findings for policy makers and physical activity providers for the design and implementation of inclusive community-based activity opportunities for people with LTCs. The results provide an opportunity for shared learning and for parkrun to demonstrate how approaches to promoting physical activity among people with LTCs work on a wide scale. There is a need to; i) be clear about how to measure the impact of such interventions, ii) be realistic about the potential to make significant change to health and behaviour, especially if implementation is dependent on the voluntary sector, iii) meet the needs of the communities being targeted, iv) ensure good communication channels that reach the target audience and, v) recruit Outreach Ambassadors, champions or community role models that have qualities such as passion and experience of the LTC. parkrun's PROVE project could be an exemplar of how communitybased social support networks can be used to support people with LTCs to self-manage their condition and overcome barriers to physical activity. The research team plan to disseminate the findings from the PROVE project evaluation to enable important learnings to be shared.

\section{Evaluation}

The results of this research should be considered in light of the following methodological issues. The findings reflect the views of self-selecting parkrun Outreach Ambassadors only and therefore might not be representative of the views of parkrun participants who have LTCs or the wider population of people living with LTCs. The experience of parkrun participants who may have had a negative experience of parkrun has not been captured in this study. A similar critique has been highlighted in previous parkrun research [13]. A limitation of the methodology is that the same researcher, who is a registered parkrun participant, conducted the interviews and analysed the data, so the findings should be interpreted with potential for bias in mind. However, the researcher's familiarity with parkrun was believed to facilitate the conduct of the interviews (i.e., in establishing rapport) and the researcher engaged in reflective practice to bring awareness to any preconceptions, beliefs and opinions about parkrun and the advantages and disadvantages that brought to the analysis of data. Furthermore, the analysis of data utilised a group of independent 'critical friends' as a research tool to help refine themes. The decision to include participants with different types of experience (i.e., people living with, caring for someone or working within the LTC) was a pragmatic decision given that all Outreach Ambassadors appointed by parkrun were invited to interview. However, the current research does not explicitly explore differences in perceptions by respondent category. Although this introduces methodological inconsistency in participant type, the researcher was careful to check for contrasting opinions in the analysis of data.

\section{Conclusions}

The need for inclusive community physical activity opportunities that are appropriate for people with LTCs, delivered in a structured manner and communicated appropriately are a priority. Parkrun's PROVE project has 
the potential to ensure that parkrun remains an inclusive and welcoming environment for people with LTCs to engage in physical activity and/or volunteering. The findings from this study have important implications for policy makers and physical activity providers wishing to design, deliver and evaluate community-based physical activity opportunities for people with LTCs.

\section{Abbreviations}

LTC(s): Long term condition(s); PROVE: parkrun running or volunteering for everyone; RCGP: Royal College of General Practitioners

\section{Acknowledgements}

The authors would like to acknowledge Gabbi Frith, Helen Speake and Liam Humphreys for acting as 'critical friends' in the coding of data. Thanks to Katie Pickering and Liam Humphries for their helpful advice during the preparation of this manuscript. We would also like to thank Frank Jones for his ongoing support with the evaluation of the PROVE project.

\section{Authors' contributions}

$\mathrm{SH}$ obtained the funding and made substantial contributions to the conception of the PROVE evaluation. HQ made substantial contribution to the conception of the study, collected and analysed the data and drafted the manuscript. SH made substantial contributions to the critical revision of the manuscript. Both authors have read and approved the final version of the manuscript.

\section{Funding}

Parkrun commissioned Sheffield Hallam University to conduct the independent evaluation of the PROVE project. This research forms part of the evaluation. The funding body (parkrun) were not involved in the conduct of this research or writing of the manuscript. Frank Jones (parkrun) approved the final version of this manuscript.

\section{Availability of data and materials}

The anonymised datasets used and/or analysed during the current study are available from the corresponding author on reasonable request.

\section{Ethics approval and consent to participate}

The research design and consent procedures were reviewed and approved by Sheffield Hallam University Research Ethics Committee. Written informed consent was received from all participants.

\section{Consent for publication}

Not applicable.

\section{Competing interests}

$\mathrm{HQ}$ and $\mathrm{SH}$ are both parkrun registrants and members of the parkrun research board at the Advanced Wellbeing Research Centre (AWRC) at Sheffield Hallam University.

\section{Author details}

${ }^{1}$ Centre for Sport and Exercise Science, Sheffield Hallam University, Sheffield S10 2BP, UK. ${ }^{2}$ Advanced Wellbeing Research Centre (AWRC), Sheffield Hallam University, Sheffield, UK

Received: 11 January 2019 Accepted: 24 September 2019

\section{Published online: 17 October 2019}

\section{References}

1. NHS England. Making the case for the personalised approach. 2018 07/11/ 2018; Available from: https://www.england.nhs.uk/blog/making-the-case-forthe-personalised-approach/

2. De Silva, D. Helping people help themselves. 2011 07/11/2018; Available from: https://www.health.org.uk/sites/health/files/ HelpingPeopleHelpThemselves.pdf.

3. Public Health England. A guide to community-centred approaches for health and wellbeing. 2015 [10th Dec 2018]; Available from: https://assets. publishing.service.gov.uk/government/uploads/system/uploads/attachment
data/file/417515/A_guide_to_community-centred_approaches_for_health_ and_wellbeing_full_repor/t_pdf.

4. Dairo YM, et al. Physical activity levels in adults with intellectual disabilities: a systematic review. Prev Med Rep. 2016:4:209-19.

5. Carroll DD, et al. Vital signs: disability and physical activity--United States, 2009-2012. MMWR Morb Mortal Wkly Rep. 2014;63(18):407-13.

6. Stubbs B, et al. How much physical activity do people with schizophrenia engage in? A systematic review, comparative meta-analysis and metaregression. Schizophr Res. 2016;176(2-3):431-40.

7. Rimmer JH. The conspicuous absence of people with disabilities in public fitness and recreation facilities: lack of interest or lack of access? Am J Health Promot. 2005;19(5):327-9.

8. Ussher $\mathrm{M}$, et al. Physical activity preferences and perceived barriers to activity among persons with severe mental illness in the United Kingdom. Psychiatr Serv. 2007;58(3):405-8.

9. Rimmer $\mathrm{JH}$, Marques AC. Physical activity for people with disabilities. Lancet. 2012;380(9838):193-5.

10. National Institute for Health and Care Excellence (NICE). Community engagement: improving health and wellbeing and reducing health inequalities. 2016 [7th Nov 2018]; Available from: https://www.nice.org.uk/guidance/ng44.

11. Public Health England. Health matters: getting every adult active every day. 2016 [13th Dec 2018]; Available from: https:/www.gov.uk/government/publications/ health-matters-getting-every-adult-active-every-day/health-matters-getting-everyadult-active-every-day\#physical-activity-and-health-inequalities.

12. parkrun. parkrun UK 2017 Run Report. 2018 [July 2018]; Available from: https://issuu.com/parkrun/docs/parkrun 2017 issuu v4.1.

13. Hindley D. "More Than Just a Run in the Park": An Exploration of Parkrun as a Shared Leisure Space. Leis Sci. 2018:1-21.

14. Stevinson C, Wiltshire G, Hickson M. Facilitating participation in healthenhancing physical activity: a qualitative study of parkrun. Int J Behav Med. 2015:22(2):170-7.

15. Morris $\mathrm{P}, \mathrm{Scott} \mathrm{H}$. Not just a run in the park: a qualitative exploration of parkrun and mental health, Adv Ment Health. 2019:7(2):110-123.

16. Grunseit A, Richards J, Merom D. Running on a high: parkrun and personal well-being. BMC Public Health. 2018;18(1):59.

17. National Voices. parkrun: lifestyle medicine for people with long term conditions. 2018 [6th Aug 2019]; Available from: https://www.nationalvoices. org.uk/blogs/parkrun-lifestyle-medicine-people-long-term-conditions.

18. Stevinson C, Hickson M. Exploring the public health potential of a mass community participation event. J Public Health. 2013;36(2):268-74.

19. Rimmer JH. Equity in active living for people with disabilities: less talk and more action. Prev Med. 2017:95:\$154-6.

20. Sparkes AC, Smith B. Qualitative research methods in sport, exercise and health: From process to product. New York: Routledge/Taylor \& Francis Group; 2014.

21. Braun V, Clarke V. Using thematic analysis in psychology. Qual Res Psychol. 2006:3(2):77-101

22. Costa AL, Kallick B. Through the lens of a critical friend. Educ Leadersh. 1993;51:49.

23. Hoekstra F, et al. National approaches to promote sports and physical activity in adults with disabilities: examples from the Netherlands and Canada. Disabil Rehabil. 2019:41(10):1217-1226.

24. Drum $\mathrm{CE}_{\text {, et }}$ al. Guidelines and criteria for the implementation of community-based health promotion programs for individuals with disabilities. Am J Health Promot. 2009:24(2):93-101.

25. Wiltshire G, Stevinson C. Exploring the role of social capital in communitybased physical activity: qualitative insights from parkrun. Qual Res Sport Exerc Health. 2018;10(1):47-62.

26. Fullagar, S. Parkrun is an important movement-and should remain free for participants. 2016 [6th Aug 2019]; Available from: https://theconversation. com/parkrun-is-an-important-movement-and-should-remain-free-forparticipants-58097.

27. Reece $L$, et al. Bright spots, physical activity investments that work: Parkrun; a global initiative striving for healthier and happier communities. Br J Sports Med. 2019;53(6):326-7.

28. Royal College of General Practioners. parkrun practice Initiative. 201813 Aug 2019; Available from: https://r1.dotdigital-pages.com/p/49LX-52M/ parkrunpractice.

\section{Publisher's Note}

Springer Nature remains neutral with regard to jurisdictional claims in published maps and institutional affiliations. 